\title{
KEBUTUHAN KETERAMPILAN MENGAJAR BAGI CALON GURU DAN GURU PENDIDIKAN IPS
}

\author{
Supentri \\ Universitas Riau \\ supentri@lecturer.unri.ac.id
}

\begin{abstract}
Abstrak
Mengajar merupakan pekerjaan Profesional yang memerlukan keahlian khusus yang ditempuh melalui Pendidikan dan Pengalaman. Untuk dapat melaksanakan Tugas dan Tanggung Jawab secara Profesional, Guru harus memiliki Kemampuan dan Keterampilan Mengajar secara Teori maupun Praktek. Kemampuan Mengajar merupakan perpaduan antara Kemampuan Intelektual, Keterampilan Mengajar, Bakat dan Seni. Keterampilan Mengajar dapat dilatih secara terus-menerus melalui Pelatihan Mengajar. Fenomena dilapangan bahwa keterampilan mengajar mahasiswa jurusan P.IPS belum maksimal dan berakibat kepada mahasiswa tidak mau masuk kelas, berdasarkan informasi beberapa guru, penyebab tidak mau masuk mengajar adalah karena tidak bisa mengelola kelas dengan baik. Oleh karena itu kemampuan atau keterampilan apa saja yang diperlukan sehingga calon guru bisa maksimal didalam kelas. Berdasarkan hasil penelitian bahwa 9 keterampilan mengajar yaitu (1) keterampilan bertanya, (2) memberi penguatan, (3) mengadakan variasi, (4) kemampuan menjelaskan, (5) membuka (6) menutup pelajaran (7) membimbing diskusi kecil, (8) mengelola kelas, dan (9) mengajar kelompok kecil dan perorangan adalah sangat penting bagi guru berdasarkan analisis yang menjawab sangat penting ditambah dengan jawaban.
\end{abstract}

Kata kunci: Keterampilan Mengajar, guru P.IPS

\section{TEACHING SKILLS NEEDS FOR PROSPECTIVE TEACHERS AND P.IPS TEACHERS}

\author{
Supentri \\ Universitas Riau \\ supentri@lecturer.unri.ac.id
}

\begin{abstract}
Teaching is a professional job that requires specific skills that are achieved through education and experience. To be able to carry out their duties and responsibilities professionally, teachers must have the ability and skills to teach in theory and practice. Teaching Ability is a combination of Intellectual Ability, Teaching Skill, Talent and Art. Teaching Skills can be trained continuously through Teaching Training. The phenomenon in the field is that the teaching skills of P.IPS study program students are not maximized and result in students not wanting to go to class, based on information from several teachers, the reason for not wanting to teach is because they can't manage the class. well. Therefore, what abilities or skills are needed so that prospective teachers can maximize their performance in the classroom. Based on the results of the study, there were 9 teaching skills, namely (1) asking skills, (2) giving reinforcement, (3) doing variations, (4) explaining skills, (5) opening (6) closing lessons (7) guiding small discussions, (8) managing the class, and (9) teaching small groups and individuals is very important for teachers based on the analysis of answers very important plus answers.
\end{abstract}

Keywords: Teaching Skills, P.IPS teacher 


\section{PENDAHULUAN}

Guru atau pendidik yang baik adalah, mereka yang berhasil membawa peserta didik mencapai tujuan dan hasil yang baik sesuai dengan kaidah yang berlaku dalam suatu pendidikan. Untuk mencapai efektifitas suatu pembelajaran, tentunya dibutuhkan seorang guru profesional yang betul-betul memahami tentang bagaimana melaksanakan suatu pembelajaran dengan baik, serta memiliki ketrampilan (skill) dasar mengajar yang baik sebelum melaksankan tugas sebagai seorang pendidik atau guru.

Keterampilan mengajar tidak begitu saja bisa diaplikasikan dalam pembelajaran namun perlu latihan sehingga keterampilan tersebut benar-benar dijiwai oleh seorang guru. Sejalan dengan tujuan pendidikan nasional maka seorang guru mempunyai fungsi dan peran yang sangat penting seperti yang tertuang dalam Undang-undang Nomor 14 Tahun 2005 tentang guru dan dosen, bahwa seorang guru mempunyai kedudukan sebagai tenaga professional pada jenjang pendidikan dasar, pendidikan menengah, dan pendidikan anak usia dini pada jalur pendidikan formal yang diangkat sesuai dengan peraturan perundang-undangan

Mengajar merupakan pekerjaan Profesional yang memerlukan keahlian khusus yang ditempuh melalui Pendidikan dan Pengalaman. Untuk dapat melaksanakan Tugas dan Tanggung Jawab secara Profesional, Guru harus memiliki Kemampuan dan Keterampilan Mengajar secara Teori maupun Praktek. Kemampuan Mengajar merupakan perpaduan antara Kemampuan Intelektual, Keterampilan Mengajar, Bakat dan Seni. Keterampilan Mengajar dapat dilatih secara terus - menerus melalui Pelatihan Mengajar.

Fenomena dilapangan bahwa keterampilan mengajar mahasiswa Jurusan Pendidikan IPS belum maksimal dan berakibat kepada mahasiswa tidak mau masuk kelas, berdasarkan informasi beberapa guru, penyebab tidak mau masuk mengajar adalah karena tidak bisa mengelola kelas dengan baik. Oleh karena itu kemampuan atau keterampilan apa saja yang diperlukan sehingga calon guru bisa maksimal didalam kelas.

Tidak tertutup kemungkinan bahwa guru dalam mengajar tidak mempunyai keterampilan untuk mengajar seperti keterampilan bertanya, membuka dan menutup pelajaran dan lain-lain. Maka melalui penelitian ini keterampilan mana saja yang dibutuhkan oleh seorang guru atau calon guru dalam mengajar 


\section{METODE PENELITIAN}

Penelitian ini dilaksanakan pada calon guru sebanyak 15 Orang dan guru P.IPS sebanyak 15 orang. Dalam penelitian ini peneliti ingin mengetahui kebutuhan keterampilan mengajar dalam proses mengajar.

\section{HASIL DAN PEMBAHASAN}

Kemampuan mengajar didalamnya ada kemampuan intelektual, keterampilan mengajar, di iringi dengan bakat dan seni. Menjadikan kegiatan mengajar itu sesuatu yang menyenangkan. Agar kemampuan mengajar tersebut bisa sampai pada tarap yang menyenangkan, ada sejumlah keterampilan (teaching skills) yang harus dilakukan dalam skala mikro. Pembelajaran mikro merupakan metode pembelajaran atas dasar performa yang tekniknya dilakukan dengan cara melatihkan komponen-komponen kompetensi dasar mengajar (teacing skill) dalam proses pembelajaran yang disederhanakan ditinjau dari aspek kompetensi mengajar, penguasaan materi, pengelolaan peserta didik, maupun mengelola waktu. Pembelajaran mikro diarahkan dalam rangka pembentukan kompetensi calon guru sebagai agen pembelajaran seperti yang termuat dalam UU Nomor 14 Tahun 2005

Keterampilan mengajar merupakan kompetensi kompetensi professional guru yang cukup kompleks, karena merupakan interaksi dari berbagai kompetensi guru secara utuh dan menyeluruh. Ada delapan keterampilan mengajar yang berperan terhadap kualitas pembelajaran yaitu (1) keterampilan bertanya, (2) memberi penguatan, (3) mengadakan variasi, (4) kemampuan menjelaskan, (5) membuka dan menutup pelajaran (6) membimbing diskusi kecil, (7) mengelola kelas, dan (8) mengajar kelompok kecil dan perorangan

Berdasarkan hasil penelitian bahwa keterampilan membuka pelajaran adalah sebagai berikut

Tabel 1. Keterampilan membuka pelajaran

\begin{tabular}{clcc}
\hline No & Alternatif Jawaban & F & Persentase (\%) \\
\hline 1 & Sangat Penting & 23 & 75 \\
2 & Penting & 7 & 25 \\
3 & Kurang Penting & & \\
4 & Tidak Penting & & 100 \\
& $\quad$ Jumlah & 30 & \\
\hline
\end{tabular}


Berdasarkan hasil penelitian bahwa keterampilan membuka pelajaran sangat penting sebesar 23 responden atau $75 \%$ dan yang menjawab penting 7 orang atau $25 \%$ jawaban kurang penting dan tidak penting tidak ada, artinya bahwa keterampilan membuka pelajaran itu sangat penting bagi seorang guru.

Selanjutnya keterampilan menjelaskan Keterampilan memberikan penjelasan adalah penyajian informasi secara lisan yang dikelola secara sistimatis untuk menunjukkan adanya hubungan antara satu dengan yang lainnya, berikut jawaban responden tentang pentingnya keterampilan menjelaskan

Tabel 2. Keterampilan menjelaskan

\begin{tabular}{clcc}
\hline No & Alternatif Jawaban & F & Persentase (\%) \\
\hline 1 & Sangat Penting & 21 & 70 \\
2 & Penting & 8 & 27 \\
3 & Kurang Penting & 1 & 3 \\
4 & Tidak Penting & & 100 \\
& $\quad$ Jumlah & 30 & \\
\hline
\end{tabular}

Berdasarkan Tabel 2 bahwa keterampilan menjelaskan materi pelajaran sangat penting sebanyak 21 atau $70 \%$, penting sebanyak 8 orang atau $27 \%$ sedangkan kurang penting 1 orang atau $3 \%$ dan tidak penting tidak ada. Artinya keterampilan menjelaskan sangat penting dalam proses mengajar.

Selanjutnya keterampilan variasi adalah suatu kegiatan guru dalam konteks proses interaksi belajar-mengajar yang ditunjuk untuk mengatasi kebosanan murid, sehingga dalam situasi proses belajar mengajar murid senantiasa menunjukkan ketekunan, antusias serta penuh partisipasi. Berikut hasil penelitian tentang pentingya keterampilan variasi dalam mengajar

Tabel 3. Keterampilan Variasi

\begin{tabular}{clcc}
\hline No & Alternatif Jawaban & F & Persentase (\%) \\
\hline 1 & Sangat Penting & 16 & 53 \\
2 & Penting & 14 & 47 \\
3 & Kurang Penting & & \\
4 & Tidak Penting & & \\
& $\quad$ Jumlah & 30 & 100 \\
\hline
\end{tabular}


Berdasarkan tabel 3 bahwa sangat penting 16 orang atau 53\%, selanjutnya penting 14 orang atau $47 \%$ sementara jawaban kurang penting dan tidak penting tidak ada. Dapat berdasarkan jawaban responden dapat disimpulkan keterampilan variasi dalam mengajar sangat penting sehingga peserta didik tidak bosan.

Penguatan Pujian" merupakan kata kata yang mengandung kekuatan dan sangat besar peranannya dalam pendidikan, apalagi kalau pujian tersebut diberikan tepat pada waktunya. Pujian berlaku untuk semua umur, bukan anak kecil saja senang dipuji, tetapi orang tua, muda, remaja, anak-anak, laki-laki dan wanita semua senang dipuji berikut hasil jawaban responden tentang pentingya keterampilan penguatan dalam mengajar.

Tabel 4. Keterampilan Penguatan

\begin{tabular}{clcc}
\hline No & Alternatif Jawaban & F & Persentase (\%) \\
\hline 1 & Sangat Penting & 14 & 47 \\
2 & Penting & 15 & 50 \\
3 & Kurang Penting & 1 & 3 \\
4 & Tidak Penting & & \\
$\quad$ & Jumlah & 30 & 100 \\
\hline
\end{tabular}

Berdasarkan tabel 4 jawaban responden terhadap pentingnya keterampilan penguatan yaitu sangat penting 14 orang atau 47\%, penting 15 orang atau 50\%, kurang penting 1 orang atau $3 \%$ dan jawaban tidak penting tidak ada, berdasarkan hasil diatas dapat disimpulkan bahwa keterampilan penguatan penting bagi guru.

Berikut adalah keterampilan bertanya yaitu salah satu cara yang efektif untuk membelajarkan siswa, dan harus diusahakan sedemikian agar pertanyaan merupakan bagian penting dari proes belajar-mengajar di sekolah berikut jawaban responden terhadap pentingnya keterampilan bertanya

Tabel 5. Keterampilan Bertanya

\begin{tabular}{clcc}
\hline No & Alternatif Jawaban & F & Persentase (\%) \\
\hline 1 & Sangat Penting & 9 & 30 \\
2 & Penting & 19 & 63 \\
3 & Kurang Penting & 2 & 7 \\
4 & Tidak Penting & & \\
\hline
\end{tabular}




\begin{tabular}{cccc}
\hline No & Alternatif Jawaban & F & Persentase (\%) \\
\hline Jumlah & 30 & 100
\end{tabular}

Dari tabel 5 diatas dapat jelaskan bahwa keterampilan bertanya sangat penting sebesar 9 orang atau $30 \%$, selanjutnya penting sebesar 19 orang atau $63 \%$ sementara yang mejawab kurang penting 2 orang atau $7 \%$ dan yang menjawab tidak penting tidak ada, kesimpulannya adalah keterampilan bertanya penting bagi guru dalam mengajar.

Keterampilan mengelola kelas mengelola kelas adalah keterampilan dalam menciptakan dan mempertahankan kondisi yang optimal guna terjadinya proses pembelajaran yang selalu serasi dan efektif. Berikut jawaban responden terhadap keterampilan mengelola kelas.

Tabal 6 Keterampilan mengelola kelas

\begin{tabular}{clcc}
\hline No & Alternatif Jawaban & F & Persentase (\%) \\
\hline 1 & Sangat Penting & 19 & 62 \\
2 & Penting & 11 & 38 \\
3 & Kurang Penting & & \\
4 & Tidak Penting & & 100 \\
& $\quad$ Jumlah & 30 & \\
\hline
\end{tabular}

Berdasarkan tabel 6 jawaban responden terhadap keterampilan mengelola kelas yaitu sangat penting sebanyak 19 orang atau 62\%, selanjutnya penting yaitu sebesar 11 orang atau $38 \%$ dan yang menjawab kurang penting, tidak penting tidak ada. Berdasarkan hasil penelitian ini keterampilan mengelola kelas sangat penting.

Ketarampilan membimbing individu, Salah satu prinsip pengajaran kelompok kecil dan perorangan adalah terjadi nya hubungan yang akrab dan sehat antara guru siswa dan siswa-siswa berikut jawaban responden terhadap keterampilan membimbing individu.

Tabel 7. Keterampilan membimbing individu

\begin{tabular}{clcc}
\hline No & Alternatif Jawaban & F & Persentase (\%) \\
\hline 1 & Sangat Penting & 11 & 37 \\
2 & Penting & 18 & 60 \\
3 & Kurang Penting & 1 & 3 \\
4 & Tidak Penting & & \\
$\quad$ & Jumlah & 30 & 100 \\
\hline
\end{tabular}


Berdasarkan tabel 7 bahwa jawaban responden sangat penting yaitu 11 orang atau 37\%, jawaban penting 18 orang atau 60\%, jawaban kurang penting 1 orang atau 3\% sisanya yang menjawab tidak penting tidak ada. Jadi dapat disimpulkan bahwa keterampilan membimbing individu penting.

Keterampilan membimbing kelompok Dalam pengajaran kelompok kecil tekanan utama terletak pada penerapan keterampilan mengorganisasikan serta membimbing dan memudahkan siswa belajar. berikut disajikan jawaban responden terhadap keterampilan membimbing kelompok.

Tabel 8. Keterampilan Membimbing Kelompok

\begin{tabular}{clcc}
\hline No & Alternatif Jawaban & F & Persentase (\%) \\
\hline 1 & Sangat Penting & 14 & 48 \\
2 & Penting & 16 & 52 \\
3 & Kurang Penting & & \\
4 & Tidak Penting & & 100 \\
& $\quad$ Jumlah & 30 & \\
\hline
\end{tabular}

Berdasarkan tabel 8 maka jawaban responden sangat penting yaitu 14 orang atau 48\%, Sedangkan Penting 16 orang atau 52\% dan jawaban kurang penting dan tidak penting tidak ada, artinya keterampilan membimbing kelompok adalah penting.

Keterampian yang terakhir yaitu keterampilan menutup pelajaran kegiatan yang dilakukan guru untuk mengakhiri kegiatan inti pelajaran. Menutup pelajaran (clossure) yaitu kegiatan yang dilakukan oleh guru dalam mengakhiri kegiatan pembelajaran dengan mengemukakan kembali pokok-pokok pelajaran berikut jawaban responden tentang pentingnya keterampilan menutup pelajaran.

Tabel 9. Keterampilan menutup pelajaran

\begin{tabular}{clcc}
\hline No & Alternatif Jawaban & F & Persentase (\%) \\
\hline 1 & Sangat Penting & 16 & 53 \\
2 & Penting & 12 & 40 \\
3 & Kurang Penting & 2 & 7 \\
4 & Tidak Penting & & \\
\hline
\end{tabular}




\begin{tabular}{cccc}
\hline No & Alternatif Jawaban & $\mathrm{F}$ & Persentase (\%) \\
\hline & Jumlah & 30 & 100 \\
\hline
\end{tabular}

Berdasarkan table 9 dapat dilihat bahwa responden yang menjawab sangat penting yaitu 16 orang atau 53\% selanjutnya yang menjawab penting 12 orang aau $40 \%$ serta yang menjawab kurang penting 2 orang atau $7 \%$ dan yang menjawab tidak penting tidak ada. Jadi dapat disimpulkan bahwa keterampilan menutup pelajaran adalah sangat penting. Rekap Hasil penelitian dapat dilihat dari tabel 10 berikut :

Tabel 10 Rekapitulasi Peneltian

\begin{tabular}{|c|c|c|c|c|c|c|c|c|}
\hline \multirow{2}{*}{ No } & \multicolumn{2}{|c|}{ SP } & \multicolumn{2}{|c|}{$\mathbf{P}$} & \multicolumn{2}{|c|}{ KP } & \multicolumn{2}{|c|}{ TP } \\
\hline & $\mathbf{F}$ & $\mathbf{P}(\%)$ & $\mathbf{F}$ & $\mathbf{P}(\%)$ & $\mathbf{F}$ & $\mathbf{P}(\%)$ & $\mathbf{F}$ & $\mathbf{P}(\%)$ \\
\hline 1 & 23 & 75 & 7 & 25 & & & & \\
\hline 2 & 21 & 70 & 8 & 27 & 1 & 3 & & \\
\hline 3 & 16 & 53 & 14 & 47 & & & & \\
\hline 4 & 14 & 47 & 15 & 50 & 1 & 3 & & \\
\hline 5 & 9 & 30 & 19 & 63 & 2 & 7 & & \\
\hline 6 & 19 & 62 & 11 & 38 & & & & \\
\hline 7 & 11 & 37 & 18 & 60 & 1 & 3 & & \\
\hline 8 & 14 & 48 & 16 & 52 & & & & \\
\hline 9 & 16 & 53 & 12 & 40 & & & & \\
\hline Jumlah & 143 & 475 & 120 & 402 & 5 & 16 & & \\
\hline Rata-rata & 15,89 & 53 & 13,33 & 45 & 0,56 & 2 & & \\
\hline
\end{tabular}

Sangat Penting + Penting $(53+45)=98 \%$

Kurang penting + Tidak Penting $(2+0)=2 \%$

Apabila di analisis dengan tolak ukur telah ditentukan pada penelitian ini yaitu
a. Sangat Penting apabila mencapai $76 \%-100 \%$
b. Penting mencapai $56 \%-75 \%$
c. Kurang Penting apa bila mencapai $40 \%-55 \%$
d. Tidak Penting apa bila kurang dari 40

Berdasarkan tabel 10 diatas jawaban sangat penting ditambah jawaban penting adalah 98\% termasuk dalam kategori sangat penting yaitu antara 76\% sampai $100 \%$. Jadi dapat disimpulkan bahwa ada 9 keterampilan yaitu (1) keterampilan bertanya, (2) memberi penguatan, (3) 
mengadakan variasi, (4) kemampuan menjelaskan, (5) membuka (6) menutup pelajaran (7) membimbing diskusi kecil, (8) mengelola kelas, dan (9) mengajar kelompok kecil dan perorangan yang diperlukan oleh seorang guru dan keterampilan tersebut harus dilatih.

\section{KESIMPULAN}

Berdasarkan hasil penelitian bahwa 9 keterampilan mengajar yaitu (1) keterampilan bertanya, (2) memberi penguatan, (3) mengadakan variasi, (4) kemampuan menjelaskan, (5) membuka (6) menutup pelajaran (7) membimbing diskusi kecil, (8) mengelola kelas, dan (9) mengajar kelompok kecil dan perorangan adalah sangat penting bagi guru berdasarkan analisis yang menjawab sangat penting ditambah dengan jawaban penting yaitu sebesar $98 \%$ yaitu antara $76 \%-100 \%$ dalam kategori sangat penting

\section{DAFTAR PUSTAKA}

Endang Susantini, Abdul Kholiq, Bertha Yonata, An Nuril Maulida \& Ulfi Faizah.2014 Development Microteaching Handbook for Lecturer, student, and learning laboratory Crew Of Science and Mathematic Faculty. Internasional Journal of Education. ISSN 19485476.2014, Vol. 6, No. 3. (p.230)

F.G.A.K Wardani.1985. Pengembangan Profesi Guru. Alfabeta. Bandung

Jhon. F. Bolla. 1985. Keterampilan Mengelola Kelas. Departemen Pendidikan dan Kebudayaan

Kartikowati, Gimin dan Gani Haryana. 2014. Pengembangan Model Learner Centered Micro Teaching melalui peran kelompok untuk meningkatkan kemahiran mengajar mahasiswa Universitas Riau. Prosiding: Seminar Nasional ASPROPENDO, di PUSDIKLAT UNS, 1718 Oktober 2014

S.I.IA Sulo. 1980. Keterampilan Bertanya Dalam Proses Belajar Mengajar. Departemen Pendidikan Dan Kebudayaan

Udin Syaefudin Saud.2013. Pengembangan Profesi Guru. Alfa Beta. Bandung

Zainal asril.2015. Micro Teaching.PT Raja Grafindo.Jakarta 